\title{
A Volume Flexible Inventory Model with Trapezoidal Demand Under Inflation
}

\author{
Kapil Mehrotra \\ Graphic Era University, Dehradun \\ kapilmehrotra123@gmail.com \\ Himani Dem \\ Department of Applied Science \\ Meerut Institute of Technology \\ Meerut-250103, India \\ himanidem@gmail.com \\ S.R. Singh \\ Department of Mathematics \\ Devanagri College \\ Chaudhary Charan Singh University \\ Meerut-250001, India \\ shivrajpundir@gmail.com \\ Rajendra Sharma \\ Department of Mathematics and Statistics \\ Graphic Era University \\ Dehradun, India \\ rs.2103@yahoo.in
}

\begin{abstract}
This article explores an economic production quantity model (EPQ) model for deteriorating items with time-dependent demand following trapezoidal pattern taking the volume flexibility into account. We have also considered the inflation and time value of money. The solution of the model aims at determining the optimal production run-time in order to maximize the profit. The model is also illustrated by means of numerical experiment. Further, the effects of different parameters are analyzed by performing sensitivity analyses on the optimal policy.
\end{abstract}

Keywords: Inventory, Trapezoidal demand, Volume flexibility, Inflation.

\section{Introduction}

Generally, the researchers assumed the time varying demand as an increasing or decreasing function of time, however in reality; this hypothesis is not appropriate for all products. One can observe the two-fold ramp type pattern in demand for items like fashion apparel, particular kind of eatables and festival accessories having restricted phase for sales and becomes out of use at end of phase. Such structure is known as "trapezoidal ramp-type". In opening phase, the demand rises up to a certain time point and becomes constant later but starts falling towards the end phase. Hill (1995) was the first to consider ramp type demand through inventory modeling. After that, various researchers have drawn considerable attention to exploration of ramp-type demand. Mandal and Pal (1998) proposed the inventory model with ramp-type demand for exponentially deteriorating 
items with shortages. Wu and Ouyang (2000) developed EOQ models for different replenishment policies; one of which included shortage at beginning while the second considered shortage at later phase. Continuing in same manner, Wu (2001) investigated a model for deteriorating items with ramp-type demand and partial backlogging. Giri et al. (2003) studied an extension for ramp-type demand inventory model with Weibull distribution deterioration rate. Manna and Chaudhuri (2006) developed a production model with ramp-type two time periods regarded as demand from taking demand dependent production into account. Deng et al. (2007) got a note published on the uncertain results found by Mandal and Pal (1998) and Wu and Ouyang (2000) and proved a more reliable solution. Panda et al. (2008, 2009) worked on Giri et al.'s (2003) model to change one-fold demand model to two-fold demand. Hill's (1995) model was extended to trapezoidal-type demand rate by Cheng and Wang (2009). Panda et al. (2009) developed the inventory model with quadratic ramp-type demand function which determined the optimal production stopping time. Skouri et al. (2009) extended the model of Deng et al. (2007) to wide-ranging ramp-type demand rate, Weibull distribution deterioration rate, and general partial backlogging rate. Further, this model was extended by Hung (2011). He incorporated arbitrary component in ramp-type demand pattern. Shah and Shah (2012) investigated a model for items having trapezoidal demand in an integrated system. Inflation plays a vital role in the inventory system and production management though the decision makers may face difficulties in arriving at answers related to decision making. At present, it is impossible to ignore the effects of inflation and it is necessary to consider the effects of inflation on the inventory system. The application of this concept was initiated by Buzacott (1975), who developed an EOQ model with inflation subject to different types of pricing policies. After that, several researchers like Brahmbhatt (1982), Chandra and Bahner (1985), Datta and Pal (1991), Hariga (1995, 1996) and Ray and Chaudhuri (1997) explored the effect of inflation and time value of money on inventory models. Liao et al. (2000) developed an inventory model for initial-stock dependent consumption rate with permissible delay in payment under the inflationary environment. Moon et al. (2005) developed the model for ameliorating/deteriorating items with time varying demand pattern over a finite planning horizon and explored the effects of inflation and time value of money. Jolai et al. (2006) studied the system of perishable items for stock dependent demand and shortages with inflation. Dey et al. (2008) developed a finite time horizon inventory problem for deteriorating items for a twowarehouse system under inflation and time value of money. Roy et al. (2009) worked on inventory model for a deteriorating item with displayed stock dependent demand under fuzzy inflation and time discounting over a random planning horizon. Yang et al. (2010) discussed a model under similar environment relaxing the warehouse situation. Das et al. (2011) developed an economic production lot size model for an item with imperfect quality by considering random machine failure. Recently, Guria et al. (2013) worked on a deterministic and random planning horizon based model under inflation considering both the cases of shortage as well as no shortage.

Almost all the studies cited above, considered the constant rate of production. However, constant production rate is not always practical. For instance, as production model is based on time dependent demand, the postulation of constant production rate is 
inappropriate. Such situation leads to the relevance of variable production rate. Schweitzer and Seidmann (1991) were the first to consider changeable machine production rate. Khouja (1995) proposed an EPQ model with unit production cost based on used raw materials, occupied labor and tool wear and tear cost. Bhandari and Sharma (1999) considered the marketing cost in addition to formulating a comprehensive cost function. The related studies done by Sana et al. (2007) and Sana (2010) may be noted. Dem and Singh (2012) developed a volume flexible model for damageable items with time dependent demand. Dem and Singh (2013) investigated an EPQ model with volume flexibility under imperfect production process. Goyal et al. (2013) developed a volume flexible model with ramp type demand for ameliorating items.

In the present article, an EPQ model for deteriorating items with trapezoidal type demand rate and volume flexibility has been explored. We also assume that the inventory system is affected by inflation and time value of money. Trapezoidal demand rate is usually noticed in the case of seasonal goods. The demand rate for such items intensifies with the time up to certain level and then stabilizes but in final phase, the demand rate declines to a constant or zero. This kind of demand rate is very logical and hence, we purpose a realistic inventory replenishment policy for such inventory model. The remaining paper is planned as follows. In Section 2, we explain the assumptions and notation used throughout the modeling. In Section 3, we formulate the mathematical model and in Section 4 , the necessary conditions to find an optimal solution are described. We provide numerical example for each case to illustrate the model in section 5. Finally, the conclusion is given in section 6 .

\section{Assumptions and Notations}

\subsection{Assumptions}

1. Demand rate is dependent on time given by

where $a, b_{1}, b_{2}>0$

$$
D(t)= \begin{cases}a+b_{1} t, & 0 \leq t \leq t_{u} \\ a+b_{1} t_{u}, & t_{u} \leq t \leq t_{v} \\ a-b_{2} t, & t_{v} \leq t \leq T\end{cases}
$$

The above function is known as trapezoidal function.

2. Production rate is $\mathrm{k}$ times demand rate, where $\mathrm{k}>1$.

3. The unit production cost is dependent on production.

4. Time horizon is finite.

5. Deterioration rate is a constant.

6. The deterioration occurs when the item is effectively in stock.

7. The inflation and time value of money has been taken into consideration. 


\subsection{Notations}

$D(t) \quad$ Demand rate

$P(D(t))$ Production rate, $P(D(t))=k D(t)$

$\theta \quad$ Deterioration rate

$C_{1} \quad$ Set up cost

$C_{2} \quad$ Holding cost per unit per unit time

$S_{o} \quad$ Selling price per unit

$C(P)$ Production cost per unit given by $C(P)=R+\frac{G}{k D(t)}$

$R \quad$ Material cost per unit

$G \quad$ Factor associated with costs like labor and energy costs

$I(t) \quad$ Inventory level at any time $\mathrm{t}$

$t_{\mathrm{u}} \quad$ Time when demand becomes constant

$t_{\mathrm{v}} \quad$ Time till the demand remains constant

$t_{\mathrm{r}} \quad$ Time when the production stops

$T \quad$ Total cycle length

\section{Model Formulation}

We have considered the following different cases based on the occurrence of time points of demand in different phases.

3.1. Case (I) When $t_{v}<t_{r}$

The differential equations governing the system are given as follows:

$$
\begin{array}{ll}
\frac{d I_{11}(t)}{d t}=(k-1)\left(a+b_{1} t\right)-\theta I_{11}(t), & 0 \leq t \leq t_{u} \\
\frac{d I_{12}(t)}{d t}=(k-1)\left\{a+b_{1} t_{u}\right\}-\theta I_{12}(t), & t_{u} \leq t \leq t_{v} \\
\frac{d I_{13}(t)}{d t}=(k-1)\left(a-b_{2} t\right)-\theta I_{13}(t), & t_{v} \leq t \leq t_{r} \\
\frac{d I_{2}(t)}{d t}=-\left(a-b_{2} t\right)-\theta I_{2}(t), & t_{r} \leq t \leq T
\end{array}
$$

Solving the eq. (1)-eq. (4) using the boundary conditions, $I_{11}(0)=0$,

$$
\begin{aligned}
& I_{12}\left(t_{u}\right)=I_{11}\left(t_{u}\right), I_{13}\left(t_{v}\right)=I_{12}\left(t_{v}\right), I_{2}(T)=0, \text { We get } \\
& I_{11}(t)=-\frac{1}{\theta^{2}}\left[b_{1} k-b_{1}+\theta^{2} e^{-\theta T}\left\{\frac{1}{\theta^{2}}\left(-b_{1} k+b_{1}\right)-\frac{1}{\theta}(a-a k)\right\}\right]-\frac{1}{\theta}\left(a-a k+b_{1} t-b_{1} k t\right)
\end{aligned}
$$




$$
\begin{aligned}
& I_{12}(t)=\frac{1}{\theta}\left[T b_{1}-a+a k-T b_{1} k-T b_{1}-T b_{1} u+\frac{1}{\theta} e^{-\theta T} e^{\theta t_{u}}\left\{b_{1}-b_{1} k\right.\right. \\
& \left.\left.+\left(b_{1} k-b_{1}+a \theta-T b_{1} \theta-a k \theta+T b_{1} k \theta+T b_{1}-T b_{1} k\right) e^{-\theta t_{u}}\right\}+T b_{1} k+T b_{1} k u\right] \\
& I_{13}(t)=\frac{1}{\theta^{2}}\left(b_{2} k-b_{2}+\theta^{2} e^{\theta t_{v}} e^{-\theta T}\left(\frac{1}{\theta^{2}}\left(-b_{2} k+b_{2}\right)+\frac{1}{\theta}\left(a_{2}-a_{2} k+b_{2}(k-1) t_{v}\right)\right.\right. \\
& +\frac{1}{\theta}\left(e^{-\theta t_{v}}(k-1)\left(T b_{1}-a+T b_{1} e^{\theta t_{v}}-a e^{\theta t_{v}}-T b_{1}+T b_{1} e^{\theta t_{v}}+T b_{1} u e^{\theta t_{v}}\right)\right) \\
& \left.-\frac{1}{\theta^{2}} b_{1} e^{-\theta t_{v}}\left(e^{\theta t_{u}}-1\right)(k-1)\right)-\frac{1}{\theta}\left(a-a k-b_{2} t+b_{2} k t\right) \\
& I_{2}(t)=-\frac{1}{\theta}\left(a-b_{2} t\right)-\frac{1}{\theta^{2}}\left(b_{2}-\left(b_{2}+a \theta-T b_{2} \theta\right)\right)
\end{aligned}
$$

Present value of the holding cost is

$$
H C_{1}=C_{2}\left\{\int_{0}^{t_{u}} I_{11}(t) e^{-q t} d t+\int_{t_{u}}^{t_{v}} I_{12}(t) e^{-q t} d t+\int_{t_{v}}^{t_{r}} I_{13}(t) e^{-q t} d t+\int_{t_{r}}^{T} I_{2}(t) e^{-q t} d t\right\}
$$

Present value of the production cost is

$$
\begin{aligned}
P C_{1}=\int_{0}^{t_{u}} & \left(R+\frac{G}{k\left(a+b_{1} t\right)}\right) k\left(a+b_{1} t\right) e^{-q t} d t+\int_{t_{u}}^{t_{v}}\left(R+\frac{G}{k\left\{a+b_{1} t_{u}\right\}}\right) k\left\{a+b_{1} t_{u}\right\} e^{-q t} d t \\
& +\int_{t_{v}}^{t_{r}}\left(R+\frac{G}{k\left(a-b_{2} t\right)}\right) k\left(a-b_{2} t\right) e^{-q t} d t
\end{aligned}
$$

Present value of the sales revenue is

$$
S R_{1}=S_{0}\left\{\int_{0}^{t_{u}}\left(a+b_{1} t\right) e^{-q t} d t+\int_{t_{u}}^{t_{v}}\left(a+b_{1} t_{u}\right) e^{-q t} d t+\int_{t_{v}}^{T}\left(a-b_{2} t\right) e^{-q t} d t\right\}
$$

Present value of the total profit per unit time of the system is

$$
T P_{1}=\frac{1}{T}\left(S R_{1}-P C_{1}-H C_{1}-C_{1}\right)
$$

\subsection{Case (II) When $t_{r}<t_{v}<T$}

The differential equations governing the system are given as follows:

$$
\begin{array}{ll}
\frac{d I_{11}(t)}{d t}=(k-1)\left(a+b_{1} t\right)-\theta I_{11}(t), & 0 \leq t \leq t_{u} \\
\frac{d I_{12}(t)}{d t}=(k-1)\left\{a+b_{1} t_{u}\right\}-\theta I_{12}(t), & t_{u} \leq t \leq t_{r} \\
\frac{d I_{21}(t)}{d t}=-\left\{a+b_{1} t_{u}\right\}-\theta I_{21}(t), & t_{r} \leq t \leq t_{v}
\end{array}
$$


$\frac{d I_{22}(t)}{d t}=-\left(a-b_{2} t\right)-\theta I_{22}(t), \quad t_{r} \leq t \leq T$

Solving the eq. (13)-eq. (16) using the boundary conditions, $I_{11}(0)=0$,

$$
\begin{aligned}
& I_{12}\left(t_{u}\right)=I_{11}\left(t_{u}\right), I_{21}\left(t_{r}\right)=I_{22}\left(t_{r}\right), I_{22}(T)=0 \\
& I_{11}(t)=-\frac{1}{\theta^{2}}\left[b_{1} k-b_{1}+\theta^{2} e^{-\theta T}\left\{\frac{1}{\theta^{2}}\left(-b_{1} k+b_{1}\right)-\frac{1}{\theta}(a-a k)\right\}\right]-\frac{1}{\theta}\left(a-a k+b_{1} t-b_{1} k t\right) \\
& I_{12}(t)=\frac{1}{\theta}\left[T b_{1}-a+a k-T b_{1} k-T b_{1}-T b_{1} u+\frac{1}{\theta} e^{-\theta T} e^{\theta t_{u}}\left\{b_{1}-b_{1} k\right.\right. \\
& \left.\left.+\left(b_{1} k-b_{1}+a \theta-T b_{1} \theta-a k \theta+T b_{1} k \theta+T b_{1}-T b_{1} k\right) e^{-\theta t_{u}}\right\}+T b_{1} k+T b_{1} k u\right] \\
& I_{21}(t)=-\frac{1}{\theta}\left(-T b_{1}+a+T b_{1}+T b_{1} u-\frac{1}{\theta}\left(e ^ { - \theta T } e ^ { \theta t _ { r } } \left(b_{1} e^{-\theta t_{r}} e^{\theta t_{u}}+a k \theta-b_{1} e^{-\theta t_{r}}+b_{1} k e^{-\theta t_{r}}+a \theta e^{-\theta t_{r}}\right.\right.\right. \\
& \left.\left.-b_{1} k e^{\theta t_{u}-\theta t_{r}}-T b_{1} k \theta+T b_{1} k \theta+T b_{1} k \theta u-T b_{1} \theta e^{-\theta t_{r}}-a k \theta e^{-\theta t_{r}}+T b_{1} k \theta e^{-\theta t_{r}}+T b_{1} \theta e^{-\theta t_{r}}-T b_{1} k \theta e^{-\theta t_{r}}\right)\right) \\
& I_{22}(t)=-\frac{1}{\theta}\left(a-b_{2} t\right)-\frac{1}{\theta^{2}}\left(b_{2}-\left(b_{2}+a \theta-T b_{2} \theta\right)\right)
\end{aligned}
$$

Present value of the holding cost is

$$
H C_{2}=C_{2}\left\{\int_{0}^{t_{u}} I_{11}(t) e^{-q t} d t+\int_{t_{u}}^{t_{r}} I_{12}(t) e^{-q t} d t+\int_{t_{r}}^{t_{v}} I_{21}(t) e^{-q t} d t+\int_{t_{v}}^{T} I_{22}(t) e^{-q t} d t\right\}
$$

Present value of the production cost is

$$
P C_{2}=\int_{0}^{t_{u}}\left(R+\frac{G}{k\left(a+b_{1} t\right)}\right) k\left(a+b_{1} t\right) e^{-q t} d t+\int_{t_{u}}^{t_{r}}\left(R+\frac{G}{k\left\{a+b_{1} t_{u}\right\}}\right) k\left\{a+b_{1} t_{u}\right\} e^{-q t} d t
$$

Present value of the sales revenue is

$$
S R_{2}=S_{0}\left\{\int_{0}^{t_{u}}\left(a+b_{1} t\right) e^{-q t} d t+\int_{t_{u}}^{t_{v}}\left(a+b_{1} t_{u}\right) e^{-q t} d t+\int_{t_{v}}^{T}\left(a-b_{2} t\right) e^{-q t} d t\right\}
$$

Present value of the total profit per unit time of the system is

$$
T P_{2}=\frac{1}{T}\left(S R_{2}-P C_{2}-H C_{2}-C_{1}\right)
$$

\subsection{Case (III) When $t_{r}<t_{u}<T$}

The differential equations governing the system are given as follows:

$$
\frac{d I_{1}(t)}{d t}=(k-1)\left(a+b_{1} t\right)-\theta I_{1}(t), \quad 0 \leq t \leq t_{r}
$$


$\begin{array}{ll}\frac{d I_{21}(t)}{d t}=-\left(a+b_{1} t\right)-\theta I_{21}(t), & t_{r} \leq t \leq t_{u} \\ \frac{d I_{22}(t)}{d t}=-\left\{a+b_{1} t_{u}\right\}-\theta I_{22}(t), & t_{u} \leq t \leq t_{v} \\ \frac{d I_{23}(t)}{d t}=-\left(a-b_{2} t\right)-\theta I_{23}(t), & t_{v} \leq t \leq T\end{array}$

Solving the eq. (25)-eq. (28) using the boundary conditions, $I_{11}(0)=0, I_{21}\left(t_{r}\right)=I_{1}\left(t_{r}\right)$, $I_{21}\left(t_{u}\right)=I_{22}\left(t_{u}\right), I_{23}(T)=0$

$I_{11}(t)=-\frac{1}{\theta^{2}}\left[b_{1} k-b_{1}+\theta^{2} e^{-\theta T}\left\{\frac{1}{\theta^{2}}\left(-b_{1} k+b_{1}\right)-\frac{1}{\theta}(a-a k)\right\}\right]-\frac{1}{\theta}\left(a-a k+b_{1} t-b_{1} k t\right)$

$I_{21}(t)=b_{1}-\theta^{2} e^{-\theta T} e^{\theta t_{r}}\left(\frac{1}{\theta}\left(a-a k+b_{1} t_{r}-b_{1} k t_{r}\right)-\frac{1}{\theta}\left(a+b_{1} t_{r}\right)+\frac{b}{\theta^{2}}\right.$

$+\frac{1}{\theta^{2}}\left(b_{1} k-b_{1}+\theta^{2} e^{\theta t_{r}}\left(\frac{1}{\theta^{2}}\left(-b_{1} k+b_{1}\right)-\frac{1}{\theta^{2}}(a-a k)-\frac{1}{\theta}\left(a+b_{1} t\right)\right.\right.$

$I_{22}(t)=-\frac{1}{\theta}\left(a+b_{1} t_{u}-\frac{1}{\theta}\left(e^{-\theta T} e^{\theta t_{u}}\left(b_{1}+\left(-b_{1}+b_{1} k+a \theta-a k \theta+T b_{1} k-T b_{1} k \theta\right) e^{-\theta t_{u}}\right.\right.\right.$

$\left.\left.\left.+\left(b_{1} k+a k \theta-T b_{1} k \theta+b_{1} k \theta t_{r}+T b_{1} k \theta\right) e^{\theta t_{r}} e^{-\theta t_{u}}\right)\right)\right)$

$I_{23}(t)=-\frac{1}{\theta}\left(a-b_{2} t\right)-\frac{1}{\theta^{2}}\left(b_{2}-\left(b_{2}+a \theta-T b_{2} \theta\right)\right)$

Present value of the holding cost is

$$
H C_{3}=C_{2}\left\{\int_{0}^{t_{r}} I_{1}(t) e^{-q t} d t+\int_{t_{r}}^{t_{u}} I_{21}(t) e^{-q t} d t+\int_{t_{u}}^{t_{v}} I_{22}(t) e^{-q t} d t+\int_{t_{v}}^{T} I_{23}(t) e^{-q t} d t\right\}
$$

Present value of the production cost is

$$
P C_{3}=\int_{0}^{t_{r}}\left(R+\frac{G}{k\left(a+b_{1} t\right)}\right) k\left(a+b_{1} t\right) e^{-q t} d t
$$

Present value of the sales revenue is

$$
S R_{3}=S_{0}\left\{\int_{0}^{t_{u}}\left(a+b_{1} t\right) e^{-q t} d t+\int_{t_{u}}^{t_{v}}\left(a+b_{1} t_{u}\right) e^{-q t} d t+\int_{t_{v}}^{T}\left(a-b_{2} t\right) e^{-q t} d t\right\}
$$

Present value of the total profit per unit time of the system is

$T P_{3}=\frac{1}{T}\left(S R_{3}-P C_{3}-H C_{3}-C_{1}\right)$

Our objective is to find maximum total profit per unit time in each case, i.e., $\max T P_{i}(r)=\frac{1}{T}\left(S R_{i}-P C_{i}-H C_{i}-C_{1}\right)$ such that $0<\mathrm{r}<1, i=1,2,3$ 


\section{Solution Procedure}

The solution procedure is as follows:

Step 1. Equate the first derivatives of $T P_{m}$ in eq. (12), (24) and (36), denoted by $T P_{m}(\mathrm{r})$ with respect to $r$ to zero and solve all the three equations for $r$.

Step 2. Check for concavity. The sufficient condition for maximum $T P_{m}(\mathrm{r})$ is $\frac{d^{2} T P_{m}(r)}{d r^{2}}<0$.

Step 3. If $0 \leq r \leq 1$, calculate $T P_{m}$ from eq. (12), (24) and (36).

\section{Numerical Example and Sensitivity Analysis}

We determine the optimal value of decision variables and net profit using solution procedure defined in last section. We use the following values of the parameters in appropriate units: $\mathrm{S}_{\mathrm{o}}=100, \mathrm{~T}=12, \mathrm{k}=1.5, \mathrm{C}_{1}=100, \mathrm{C}_{2}=1, a=10, \mathrm{~b}_{1}=\mathrm{b}_{2}=0.1, \theta=0.01, \mathrm{R}=10$, $\mathrm{G}=250, \mathrm{q}=0.6, \mathrm{t}_{\mathrm{u}}=3, \mathrm{t}_{\mathrm{v}}=6$. The optimal net profit $T P_{m}{ }^{*}$ and optimal time parameter for production run time $t_{r}^{*}$ for the three cases are provided in the following table:

Table 1: Summary of results

\begin{tabular}{ccc}
\hline Case & $\boldsymbol{r}^{*}$ & $\boldsymbol{T P}_{\boldsymbol{m}}{ }^{*}$ \\
\hline I & 3 & $4.959 \mathrm{e}+20$ \\
II & 3 & $8.688 \mathrm{e}+20$ \\
III & 6 & $3.51 \mathrm{e}+20$ \\
\hline
\end{tabular}

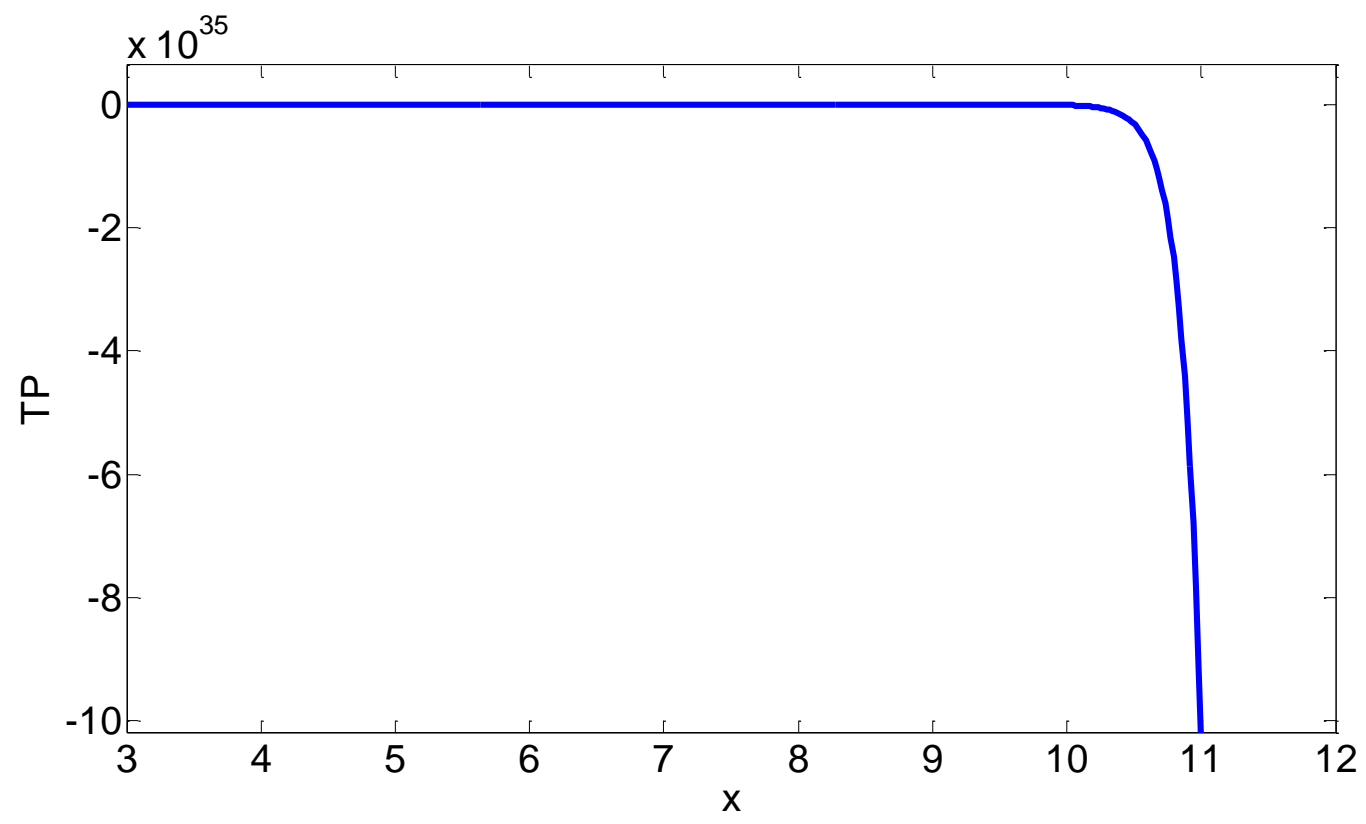

Fig. 1. Net profit in Case (I) 


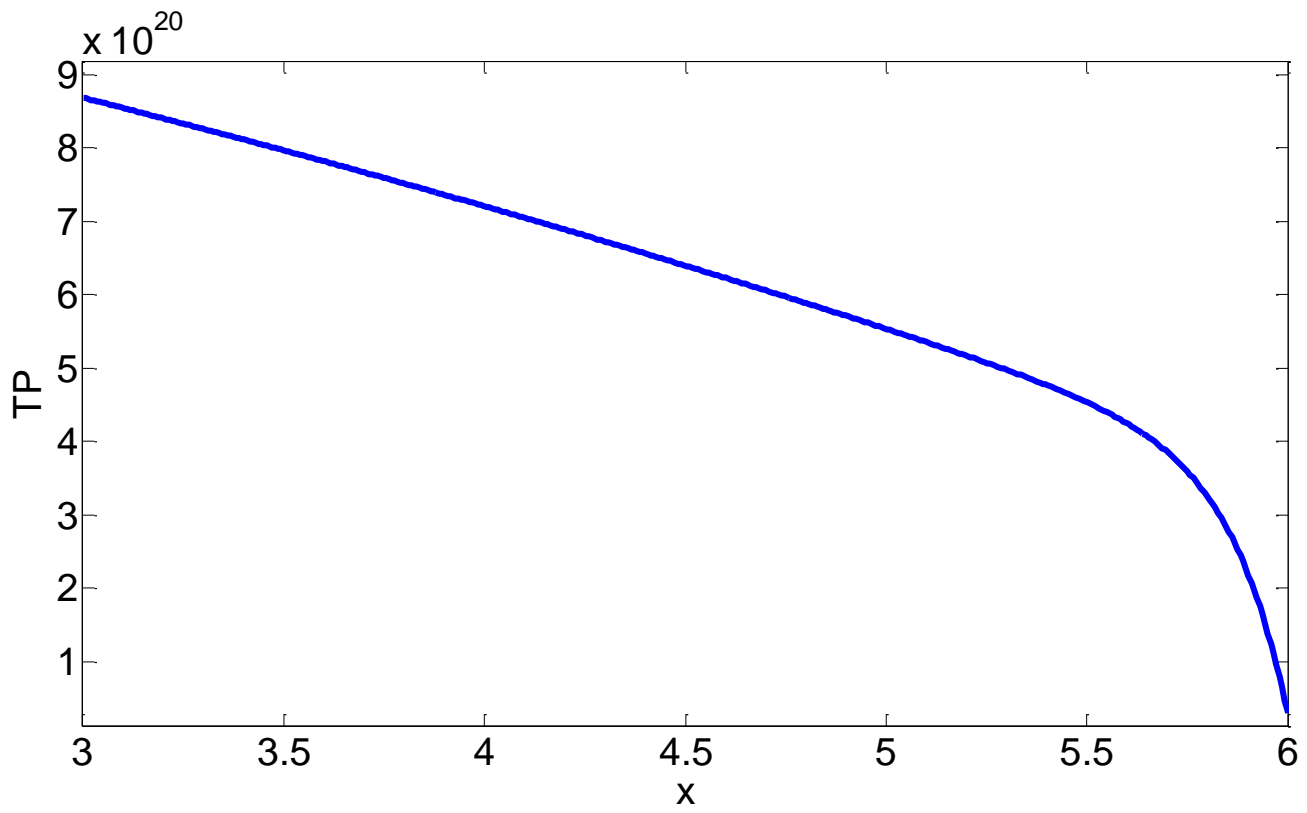

Fig. 2. Net profit in Case (II)

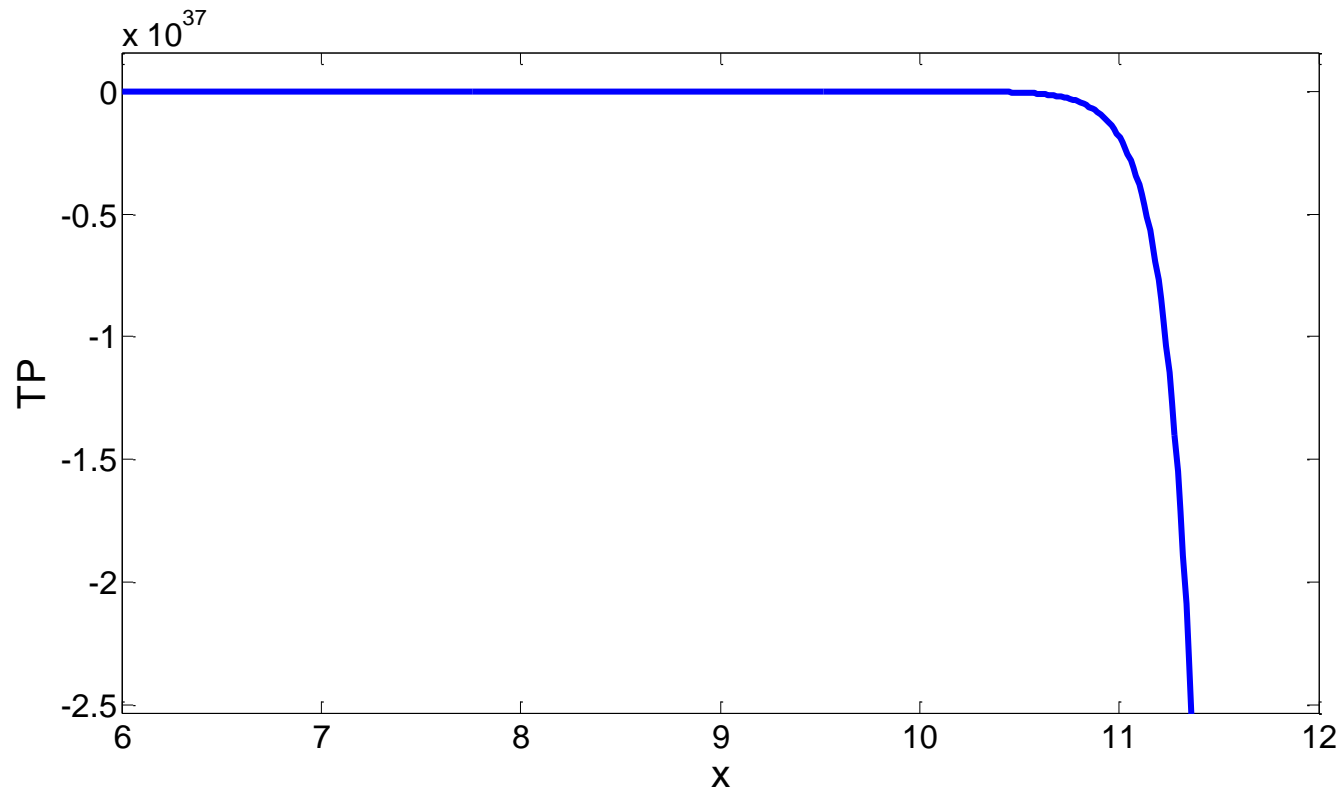

Fig. 3. Net profit in Case (III)

Based on the above experimental outcomes, sensitivity analysis is provided for Case II for which the maximum profit has achieved. It is performed by altering the parameters by $50 \%$ and $25 \%$, taking one parameter at a time while all other parameters being constant (See, Table 2). 
Table 2: Sensitivity analyses

\begin{tabular}{|c|c|c|}
\hline Parameter & Value & $T P_{m}$ \\
\hline \multirow{4}{*}{$S_{o}$} & 50 & $4.424 \mathrm{e}+20$ \\
\hline & 75 & $6.556 e+20$ \\
\hline & 125 & $1.082 \mathrm{e}+21$ \\
\hline & 150 & $1.295 \mathrm{e}+21$ \\
\hline \multirow{4}{*}{$a$} & 5 & $3.943 e+20$ \\
\hline & 7.5 & $6.316 e+20$ \\
\hline & 12.5 & $1.106 e+21$ \\
\hline & 15 & $1.343 e+21$ \\
\hline \multirow{4}{*}{$b_{1}$} & 0.05 & $6.907 e+20$ \\
\hline & 0.075 & $7.798 e+20$ \\
\hline & 0.125 & $9.579 e+20$ \\
\hline & 0.15 & $1.047 \mathrm{e}+21$ \\
\hline \multirow{4}{*}{$k$} & 0.75 & $1.022 \mathrm{e}+21$ \\
\hline & 1.125 & $9.456 e+20$ \\
\hline & 1.875 & $7.92 \mathrm{e}+20$ \\
\hline & 2.25 & $7.152 \mathrm{e}+20$ \\
\hline \multirow{4}{*}{$\theta$} & 0.005 & $8.321 e+20$ \\
\hline & 0.0075 & $8.519 \mathrm{e}+20$ \\
\hline & 0.0125 & $8.832 \mathrm{e}+20$ \\
\hline & 0.015 & $8.954 e+20$ \\
\hline \multirow{4}{*}{$t_{u}$} & 1.5 & $6.869 e+20$ \\
\hline & 2.25 & $7.768 e+20$ \\
\hline & 3.75 & $9.632 \mathrm{e}+20$ \\
\hline & 4.5 & $1.06 \mathrm{e}+21$ \\
\hline \multirow{4}{*}{$t_{v}$} & 3 & $-2.978 e+10$ \\
\hline & 4.5 & $1.169 \mathrm{e}+16$ \\
\hline & 7.5 & $5.703 e+25$ \\
\hline & 9 & $3.501 \mathrm{e}+30$ \\
\hline
\end{tabular}


The observations made from sensitivity analysis can be described as the following:

1. Total profit increases with the rising selling price $S_{o}$ which is a fairly usual occurrence.

2. Total profit intensifies with the rising initial parameter ' $a$ ' and time sensitive parameter ' $b_{1}$ ' of demand. Elevated demand of manufactured units stimulates more production which becomes a important cause to make additional profit.

3. With the increase in the coefficient related to production rate ' $k$ ', total profit decreases. Quantity of production becomes more in proportion to the demand for higher values of ' $k$ '.

4. Total profit becomes lesser with increasing value of the deterioration rate ' $\theta$ '. The larger quantity of deteriorated units leads to loss of sales that could have been added to revenue.

5. As the time points ' $t_{u}$ ' and ' $t_{v}$ ' increase, total profit increases. Since, ' $t_{u}$ ' is the point when demand stabilizes and ' $t_{v}$ ' is the point till the demand remains stable, hence their increasing values leads to the greater demand which causes higher turnover.

\section{Conclusion}

This article considers the particular items following trapezoidal ramp type demand incorporating inflation and time value of money. Three cases according to the demand have been discussed and for each case, a profit function is formulated for maximization. The condition to find the optimal solution is given and using numerical experiment, we show that the profit is maximum when the demand stabilizes before or with the production stops. Sensitivity analysis is performed corresponding to various parameters and the results confirm the authenticity of the model under study. The proposed study can be extended in various dimensions including stochastic or fuzzy modeling.

\section{References}

1. Bhandari, R. M. and Sharma, P. K. (1999). The economic production lot size model with variable cost function. Opsearch, 36, 137- 150.

2. Buzacott, J. A. (1975). Economic order quantities with inflation. Operational Research Quarterly, 26, 553-558.

3. Cheng, M. and Wang, G. (2009). A note on the inventory model for deteriorating items with trapezoidal type demand rate. Computers and Industrial Engineering, 56, 1296-1300.

4. Chandra, M., Jeya B. and Michael L. (1985). Effects of inflation and the time value of money on some inventory systems. International Journal of Production Research, 23, 723-730. 
5. Datta, T.K. and Pal, A.K. (1991). Effects of inflation and time value of money on an inventory model with linear time-dependent demand rate and shortages. European Journal of Operational Research, 52, 326-333.

6. Das, D., Roy, A. and Kar, S. (2011). A volume flexible economic production lotsizing problem with imperfect quality and random machine failure in fuzzystochastic environment. Computers and Mathematics with Applications, 61, 2388-400.

7. Dem, H. and Singh, S.R. (2012). Production scheduling for damageable items with demand and cost flexibility using genetic algorithm. Advances in Intelligent and Soft Computing, 131, 747-759.

8. Dem, H. and Singh, S.R. (2013). A production model for ameliorating items with quality consideration. International Journal of Operational Research, 17, 183-198.

9. Deng, P. S., Lin, R. H. J. and Chu, P. (2007). A note on the inventory models for deteriorating items with ramp type demand rate. European Journal of Operational Research, 178, 112-120.

10. Dey, J., Mondal, S. and Maiti, M. (2008). Two storage inventory problem with dynamic demand and interval valued lead-time over finite time horizon under inflation and time value of money. European Journal of Operational Research, $185,170-94$.

11. Goyal, S.K., Singh, S.R. and Dem, H. (2013). Production policy for ameliorating/deteriorating items with ramp type demand. International Journal of Procurement Management, 6, 444-465.

12. Giri, B. C., Jalan, A. K., and Chaudhuri, K. S. (2003). Economic Order Quantity model with Weibull deterioration distribution, shortage and ramp-type demand. International Journal of Systems Science, 34, 237-243.

13. Hill, R.M. (1995). Inventory models for increasing demand followed by level demand. Journal of the Operational Research Society, 46, 1250-1259.

14. Hung, K. C. (2011). An inventory model with generalized type demand, deterioration and backorder rates. European Journal of Operational Research, 208, 239-242.

15. Jolai, F., Moghaddam, R. T., Rabbani, M. and Sadoughian, M. R. (2006). An economic production lot size model with deteriorating items, stock-dependent demand, inflation, and partial backlogging. Applied Mathematics and Computation. 
16. Liao, H. C. and Chen, Y. K. (2003). An optimal solution of a general lot size inventory model with deteriorated and imperfect products, taking into account inflation and time value of money. International Journal of System Sciences, 34, 4-15.

17. Moon, I., Giri, B. C. and Ko, B. (2005). Economic order quantity models for ameliorating/deteriorating items under inflation and time discounting. European Journal of Operational Research, 162(3), 773-785.

18. Mandal, B. and Pal, A. K. (1998). Order level inventory system with ramp type demand rate for deteriorating items. Journal ofInterdisciplinary Mathematics, 1 , 49-66.

19. Manna, S. K. and Chaudhuri, K. S. (2006). An EOQ model with ramp type demand rate, time dependent deterioration rate, unit production cost and shortages. European Journal of Operational Research, 171, 557-566.

20. Panda, S., Saha, S. and Basu, M. (2007). An EOQ model with generalized ramptype demand and weibull distribution deterioration. Asia-Pacific Journal of Operational Research, 24, 93-109.

21. Panda, S., Senapati, S. and Basu, M. (2008). Optimal replenishment policy for perishable seasonal products in a season with ramp type time dependent demand.Computers and Industrial Engineering, 54, 301-314.

22. Panda, S., Senapati, S. and Basu, M. (2009). Optimal production stopping time for perishable products with ramp-type quadratic demand dependent production and setup cost. Central European Journal of Operations Research, 17, 381-396.

23. Sana, S. S., Goyal, S. K. and Chaudhuri, K. S. (2007).An imperfect production process in a volume flexible inventory model. International Journal of Production Economics, 105, 548-559.

24. Sana, S. S. (2010). A production-inventory model in an imperfect production process. European Journal of Operational Research, 200, 451-464.

25. Schweitzer, P. J. and Seidmann, A. (1991).Optimizing processing rates for flexible manufacturing systems. Management Science, 37, 454-466.

26. Shah, N. H. and Shah, D. B. (2012). Vendor-buyer ordering policy when demand is trapezoidal, International. Journal of Industrial Engineering Computations, 3, $721-730$.

27. Skouri, K., Konstantaras, I., Papachristos, S. and Ganas, I. (2009). Inventory models with ramp type demand rate, partial backlogging and Weibull deterioration rate. European Journal of Operational Research, 192, 79-92. 
28. Yang, H. L., Teng, J. T. and Chern, M. S.(2010). An inventory model under inflation for deteriorating items with stock-dependent consumption rate and partial backlogging shortages. International Journal of Production Economics, 123, 8-19.

29. Wu, K. S. and Ouyang, L. Y. (2000). A replenishment policy for deteriorating items with ramp type demand rate. Proceedings of the National Science Council, Republic of China A, 24, 279-286.

30. Wu, K. S. (2001). An EOQ inventory model for items with Weibull distribution deterioration, ramp type demand rate and partial backlogging. Production Planning and Control, 12, 787-793. 